\title{
BMJ Open Race-ethnic and gender differences in representation within the English National Health Service: a quantitative analysis
}

\author{
Adrienne Milner (D) , ${ }^{1}$ Elizabeth Baker, ${ }^{2}$ Samir Jeraj, ${ }^{3}$ Jabeer Butt ${ }^{3}$
}

To cite: Milner A, Baker E, Jeraj S, et al. Race-ethnic and gender differences in representation within the English National Health Service: a quantitative analysis. BMJ Open 2020;10:e034258. doi:10.1136/ bmjopen-2019-034258

- Prepublication history for this paper is available online. To view these files, please visit the journal online (http://dx.doi. org/10.1136/bmjopen-2019034258).

Received 13 September 2019 Revised 25 November 2019 Accepted 27 November 2019

Check for updates

(c) Author(s) (or their employer(s)) 2020. Re-use permitted under CC BY-NC. No commercial re-use. See rights and permissions. Published by BMJ.

${ }^{1}$ Department of Life Sciences, Brunel University London, Uxbridge, UK

${ }^{2}$ Department of Sociology, University of Alabama at Birmingham, Birmingham, Alabama, USA

${ }^{3}$ Race Equality Foundation, London, UK

Correspondence to Dr Adrienne Milner; adrienne.milner@brunel.ac.uk

\section{ABSTRACT}

Objectives To evaluate race-ethnic and gender disparities in National Health Service (NHS) England employment in position, prestige and pay.

Design National study using data from NHS Digital. Setting Trusts and clinical commissioning groups in England.

Participants 1105390 NHS Hospital and Community Health Service staff.

Results Chinese people $(42.9 \%, 95 \% \mathrm{Cl} 41.7 \%$ to $44.1 \%$ ) are the most likely to be employed as doctors, followed by Asians $(28.6 \%, 95 \% \mathrm{Cl} 28.3 \%$ to $28.8 \%)$ and people of mixed race/ethnicity $(17.9 \%, 95 \% \mathrm{Cl} 17.3 \%$ to $18.4 \%)$; while white people $(6.8 \%, 95 \% \mathrm{Cl} 6.7 \%$ to $6.8 \%$ ) are less likely to be employed as doctors. However, white doctors are the most likely to be in the highest paid positions: $46.0 \%$ (95\% Cl $45.6 \%$ to $46.4 \%$ ) of white doctors are consultants, whereas only $33.4 \%(95 \% \mathrm{Cl}$ $31.6 \%$ to $35.2 \%$ ) of Chinese doctors are consultants. Black people are under-represented both among doctors and as consultants: $6.5 \%$ (95\% $\mathrm{Cl} 6.4 \%$ to $6.7 \%$ ) of black employees are doctors and $30.6 \%(95 \% \mathrm{Cl} 29.2 \%$ to $32.0 \%$ ) of black doctors are consultants. We found similar results for nurses and health visitors, where white people are over-represented in the higher pay bands. However, among support staff for doctors, nurses and midwives, we found that Chinese people were over-represented in the higher pay bands. These race-ethnic differences were similar for women and men. Additionally, we found that men were more likely to be employed in higher pay bands than women, and this gender disparity was apparent across race-ethnic groups.

Conclusions Race-ethnic and gender disparities exist in the NHS in position, prestige and pay. To begin to overcome such disparities, the NHS must collect data using consistent race-ethnic categories in order to examine differences over time.

\section{INTRODUCTION}

Previous research ${ }^{1-3}$ has highlighted raceethnic pay disparities in the National Health Service (NHS), focusing specifically on differences among doctors. However, research has not examined race-ethnic differences in employment of doctors and other employment-type outcomes simultaneously,
Strengths and limitations of this study

Other research has examined race-ethnic pay disparities in the NHS, but it has focused primarily on disparities in pay among doctors and not examined how gender might affect conclusions.

- This study examines both race-ethnic and gender disparities in position, prestige and pay among NHS doctors, nurses and health visitors, and support staff for doctors, nurses and midwives.

- This study uses cross-sectional data from one time point, and further research is needed to examine how NHS initiatives, aimed at ensuring equality in hiring and promotion, influence outcomes over time.

nor has it examined how gender may affect this relationship. This paper seeks to answer four inter-related questions: (1) Are white individuals over-represented in more prestigious and better paying positions? (2) Do race-ethnic differences vary for women compared with men? (3) Are men overrepresented in more prestigious and higher paying positions relative to women? and; (4) Are gender disparities in prestige and pay consistent across race-ethnic groups?

The way in which various groups are overand under-represented in employment categories is important for several reasons. Differential positions result in variations in prestige, compensation and care provided. Past research indicates that diversity in the medical profession is an important contributing factor to health outcomes for raceethnic minorities and women. ${ }^{4}$ Furthermore, race-ethnic and gender disparities in representation in prestigious and high-paying NHS positions lead to further disparities in those who are appointed to decision-making positions, such as trust board members, ${ }^{5}$ which may result in adverse outcomes for the most deprived communities those trusts serve. ${ }^{6}$ 


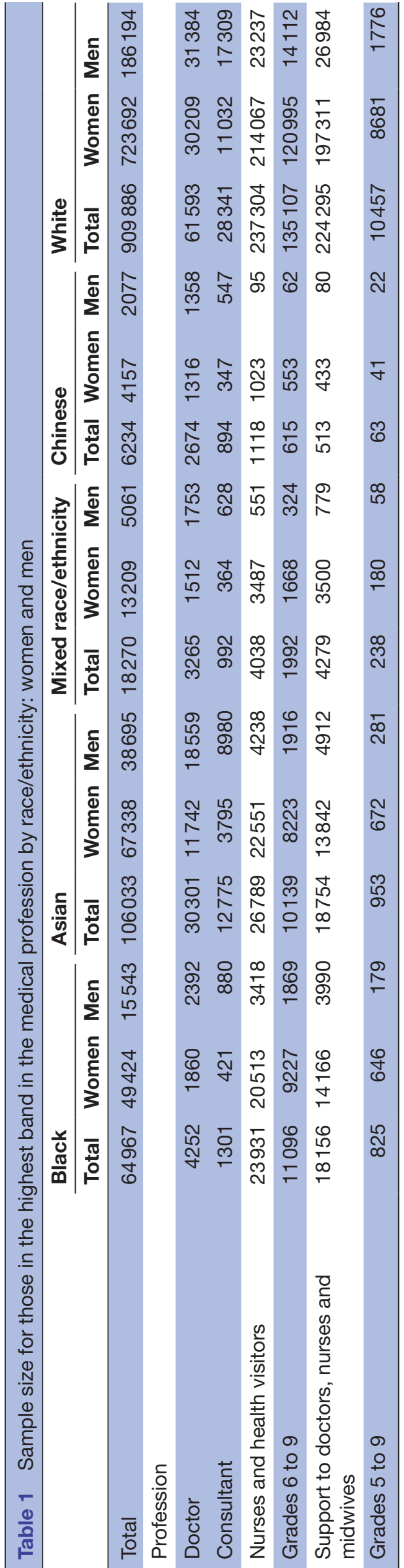

\section{METHODS}

Data and analyses

The data for this study come from the 2017 NHS Digital workforce statistics on NHS Hospital and Community Health Service ${ }^{7}$ staff groups working in trusts and clinical commissioning groups in England (excluding primary care staff). We use 2017 rather than 2018 data because certain race-ethnic codes that are important for our analysis (eg, Chinese) were discontinued in the 2018 data. Data are organised by staff group, grade, gender and race/ethnicity. Race/ethnicity and gender are selfidentified by the respondent. Race/ethnicity is categorised as Black, Asian, Chinese, mixed race/ethnicity, or White. Although Chinese people are by definition, Asian, data for this group are categorised separately because of the high proportion of Chinese doctors (42.9\%) working in NHS England. Asian refers to those people who identify as: Asian or Asian British-Indian; Asian or Asian British-Pakistani; Asian or Asian British-Bangladeshi; Asian or Asian British-any other Asian background; Asian mixed; Asian Punjabi; Asian Kashmiri; Asian East African; Asian Sri Lankan; Asian Tamil; Asian Sinhalese; Asian British; Asian Caribbean; Asian unspecified. NHS Digital categorises any person who defines themselves as belonging to the following groups as a person of mixed race/ethnicity: White and Black Caribbean; White and Black African; White and Asian; any other mixed background; Black and Asian; Black and Chinese; Black and White; Chinese and White; Asian and Chinese; other/ unspecified. Gender is categorised as women or men. This allows us to examine race-ethnic and gender variation by prestige of the job (eg, doctor vs other profession) and within a job we can examine race-ethnic disparities in prestige (eg, higher bands vs lower bands). For doctors, specifically, we examine the highest paid and most prestigious position in NHS England, consultant versus other doctors. Because of population distributions within pay bands, for nurses and health visitors, we compare grades 1 to 5 with grades 6 to 9 , and for support to doctors, nurses and midwives, we compare grades 1 to 4 with grades 5 to 9.

The data, included 116040 doctors, 317980 nurses and health visitors and 284513 support staff. Some data were missing for race/ethnicity. For doctors, in 6920 cases race/ethnicity was not stated, 2751 cases were unknown and 36 cases were given discontinued codes. For nurses and health visitors, the numbers missing for race/ ethnicity were 10638 not stated, 1980 unknown and 172 discontinued codes. For support staff, the corresponding numbers were 9185 not stated, 1654 unknown and 82 discontinued codes. It is important to note that because we examined prestige within race-ethnic groups, not having information on race/ethnicity by specific category is less concerning than not having information on band or prestige within race-ethnic groups.

We also excluded some cases from the nurses and health visitors category and some from the support to doctors, nurses and midwives category who were listed as 
Table 2 Percentage and 95\% confidence Intervals (Cls) for those in the highest band in the medical profession by race/ ethnicity: women and men

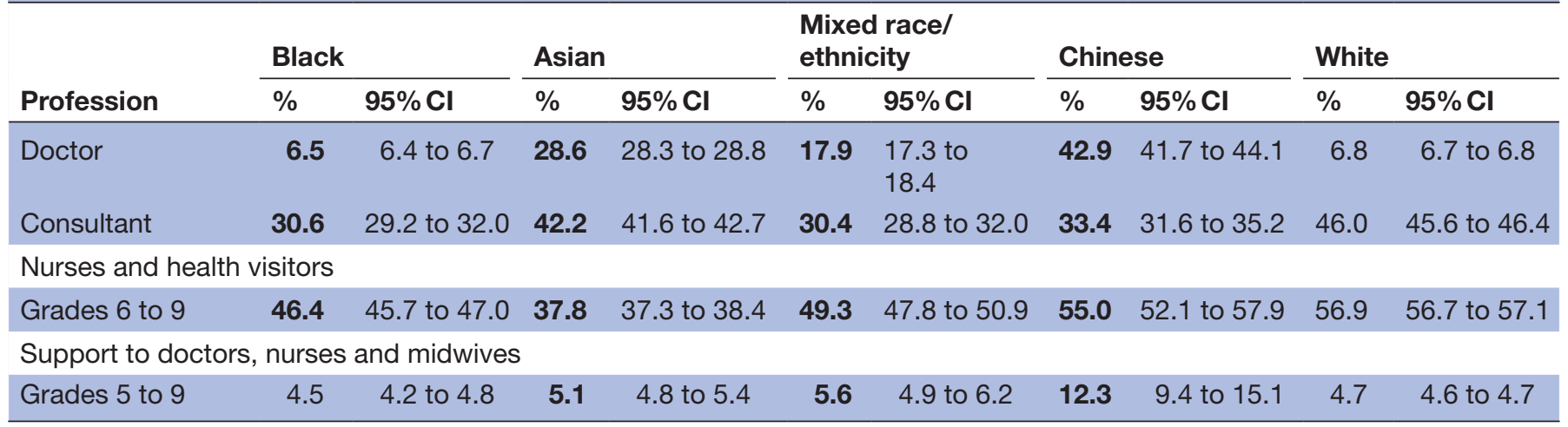

outside the Agenda for Change bands, because we could not determine their pay grade and thus prestige. For nurses and health visitors, this number was 2099 and for support staff, this number was 3217 .

To make comparisons we calculated the proportion of individuals in a higher prestige occupation by race/ ethnicity and then constructed $95 \%$ confidence intervals around these proportions using z-scores. Z-scores are used because the data are population level. For example, to calculate the proportion of doctors who are black ( $\Pi$ black doctor $)$, the SD $\left(\sigma_{\text {black doctor }}\right)$ and the $95 \%$ CI, we used the following formulas:

$$
\begin{gathered}
\Pi_{\text {black doctor }}=n_{\text {black doctor }} / n_{\text {black }} \\
\sigma_{\text {black doctor }}=\sqrt{ } \frac{\mathrm{I}_{\text {black doctor }}\left(\mathrm{I}_{\text {black doctor }}-1\right)}{N_{\text {black }}} \\
95 \% C I=\prod_{\text {black doctor }} \pm 1.96\left(\sigma_{\text {black doctor }}\right)
\end{gathered}
$$

The proportion of black doctors is calculated as the number of black doctors divided by the number of black people working in the NHS. Prestige within jobs-that is the proportion of black people who are employed in the highest band among support to doctors, nurses and midwives-is calculated as the number of black people in the higher bands among those employed as support to doctors, nurses and midwives divided by the total number of black people who are employed in this way. For these analyses, we focus on examining the extent to which different race-ethnic groups are under- or overrepresented in prestigious and higher paying jobs, net of the overall prevalence of that race-ethnic group in the NHS data. Thus, because white people comprise a majority in the NHS data, they will probably make up the majority of any job, regardless of pay band. In order to examine difference in prestige net of prevalence in the data, we focus on within-group differences in prestige. For ease of interpretation, percentages (ie, $\varpi \times 100)$ rather than proportions are displayed in the tables and graphs.

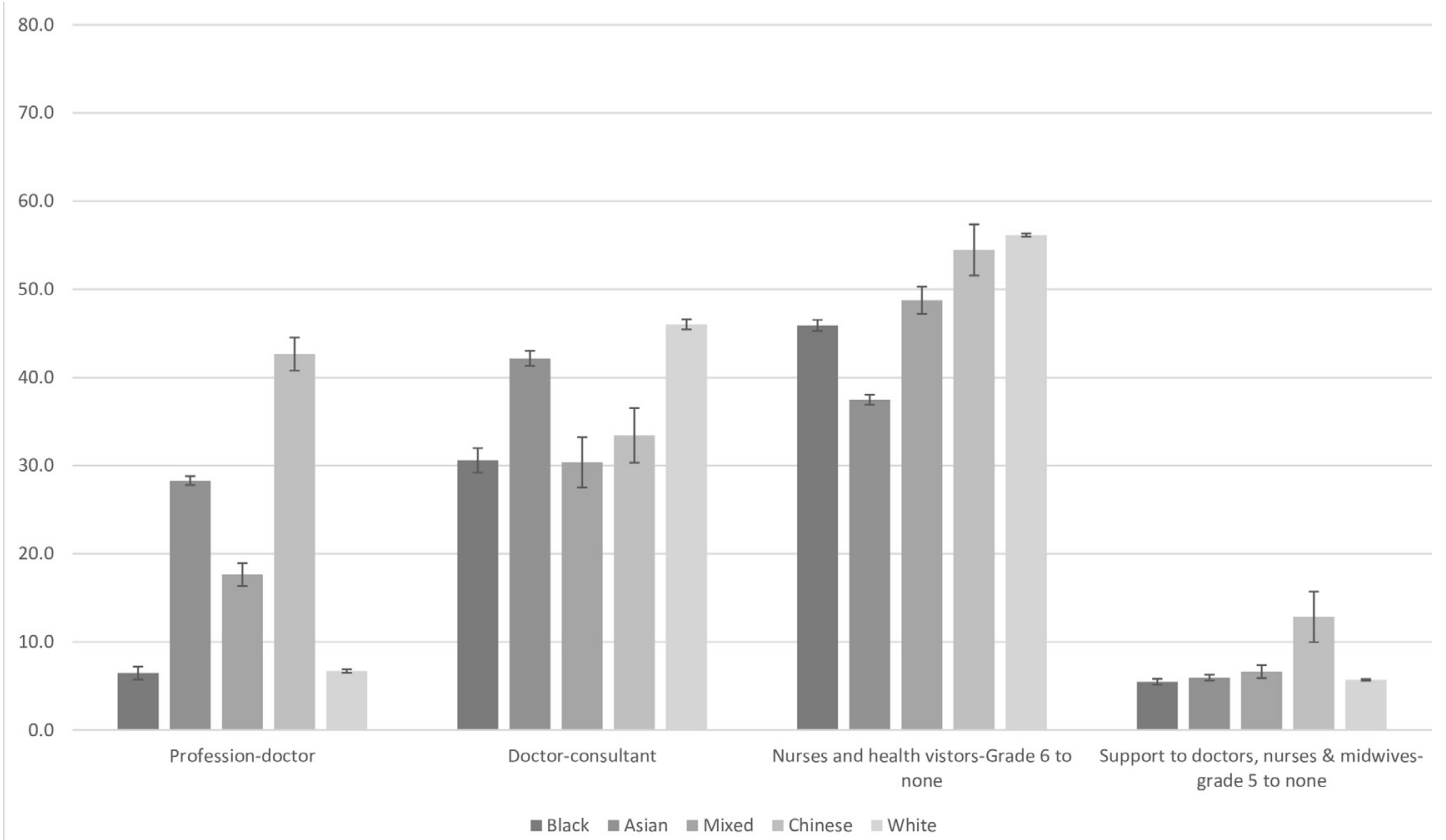

Figure 1 Percentage of those in the highest band in the medical profession by race/ethnicity: women and men. 
Table 3 Percentage and 95\% confidence Intervals (Cls) for those in the highest band in the medical profession by race/ ethnicity: women

\begin{tabular}{|c|c|c|c|c|c|c|c|c|c|c|}
\hline \multirow[b]{2}{*}{ Profession } & \multicolumn{2}{|c|}{ Black } & \multicolumn{2}{|c|}{ Asian } & \multicolumn{2}{|c|}{ Mixed race/ethnicity } & \multicolumn{2}{|c|}{ Chinese } & \multicolumn{2}{|c|}{ White } \\
\hline & $\%$ & $95 \% \mathrm{Cl}$ & $\%$ & $95 \% \mathrm{Cl}$ & $\%$ & $95 \% \mathrm{Cl}$ & $\%$ & $95 \% \mathrm{Cl}$ & $\%$ & $95 \% \mathrm{Cl}$ \\
\hline Doctor & 3.8 & 3.6 to 3.9 & 17.4 & 17.2 to 17.7 & 11.4 & 11.0 to 11.9 & 31.7 & 30.5 to 32.8 & 4.2 & 4.1 to 4.2 \\
\hline \multicolumn{11}{|c|}{ Nurses and health visitors } \\
\hline Grades 6 to 9 & 45.0 & 44.3 to 45.7 & 36.5 & 35.9 to 37.0 & 47.8 & 46.3 to 49.4 & 54.1 & 51.1 to 57.0 & 56.5 & 56.3 to 56.7 \\
\hline
\end{tabular}

\section{Patient and public involvement statement}

Patients and the public were not involved in the design, conduct, reporting or dissemination of our research.

\section{RESULTS \\ Race/ethnicity}

Table 1 displays sample sizes for those in the highest band within the medical profession by race/ethnicity for women and men. Table 2 displays the percentages and 95\% confidence intervals of higher job prestige by race/ ethnicity. This information is displayed graphically in figure 1. Within the NHS, Chinese people, Asian people and people of mixed race/ethnicity are the most likely to be employed as doctors: $42.9 \%$ (95\% CI $41.7 \%$ to $44.1 \%$ ) of Chinese people, $28.6 \%$ (95\% CI $28.3 \%$ to $28.8 \%$ ) of Asians and $17.9 \%$ (95\% CI $17.3 \%$ to $18.4 \%$ ) of people of mixed race/ethnicity are employed as doctors compared with $6.5 \%$ (95\% CI $6.4 \%$ to $6.7 \%$ ) of black people and $6.8 \%$ (95\% CI $6.7 \%$ to $6.8 \%$ ) of white people. Indeed, Chinese people were exceptionally over-represented among doctors after accounting for their overall prevalence in the NHS data.

However, although Chinese people working in the NHS are more likely to be doctors, they are less likely to be in the highest paid positions, especially relative to white people. The percentage of Chinese doctors who are consultants is $33.4 \%$ (95\% CI $31.6 \%$ to $35.2 \%$ ) compared with a percentage of $46.0 \%$ (95\% CI $45.6 \%$ to $46.4 \%$ ) for white doctors. Indeed, white doctors comprise the highest percentage of consultants compared with doctors from the other race-ethnic groups. Within the NHS, black people are under-represented both among doctors as discussed above and among consultants, with only $30.6 \%$ (95\% CI $29.2 \%$ to $32.0 \%$ ) of black doctors being consultants. A similar pattern is found for NHS nurses and health visitors, where white people in this profession occupy the higher paid positions (grades 6 to 9 ). However, among the NHS support for doctors, nurses and midwives we find that Chinese people are the most likely to be in the higher paid positions (grades 5 to 9 ).

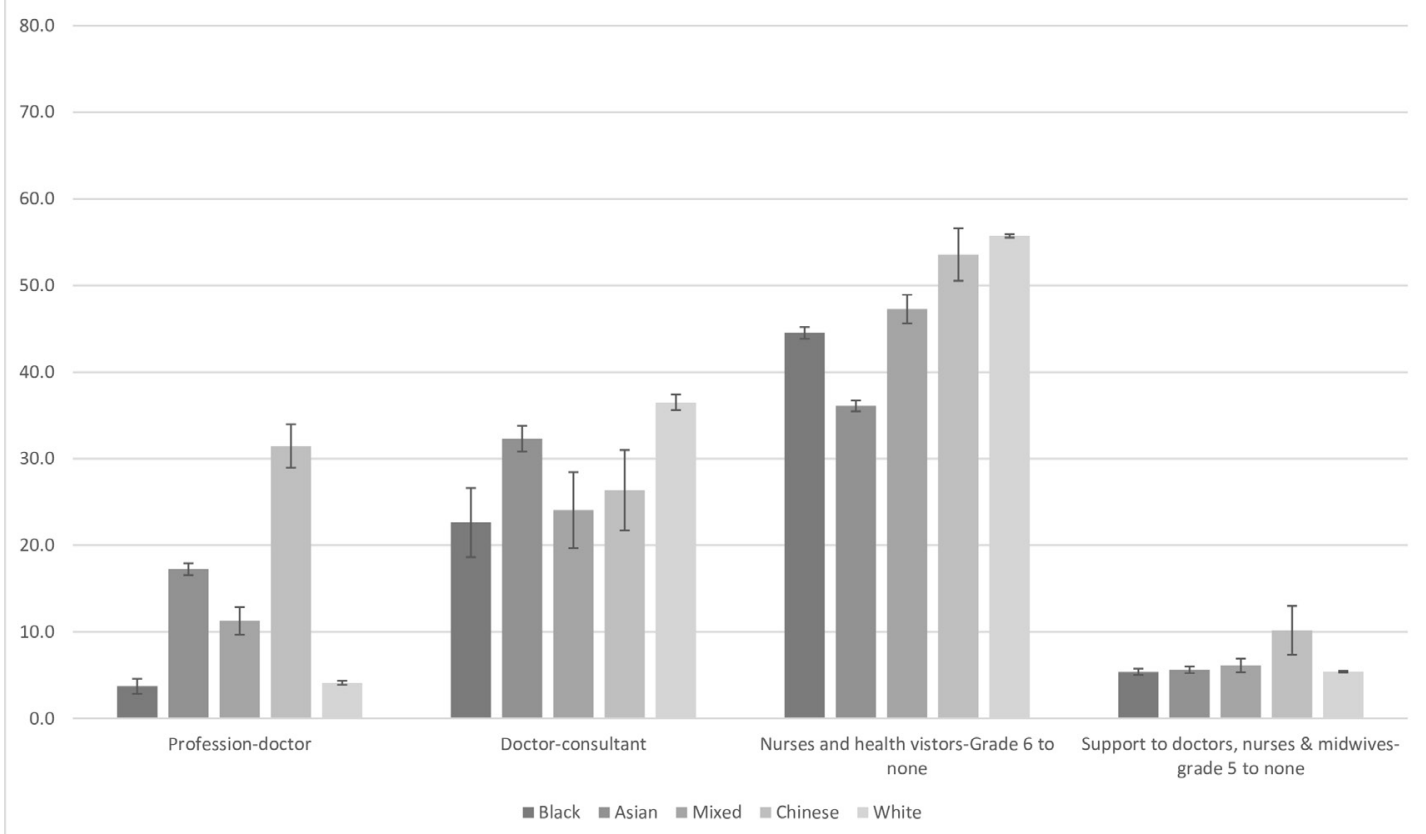

Figure 2 Percentage of those in the highest band in the medical profession by race/ethnicity: women. 
Table 4 Percentage and 95\% confidence intervals (Cls) for those in the highest band in the medical profession by race/ ethnicity: men

\begin{tabular}{|c|c|c|c|c|c|c|c|c|c|c|}
\hline \multirow[b]{2}{*}{ Profession } & \multicolumn{2}{|c|}{ Black } & \multicolumn{2}{|c|}{ Asian } & \multicolumn{2}{|c|}{$\begin{array}{l}\text { Mixed race/ } \\
\text { ethnicity }\end{array}$} & \multicolumn{2}{|c|}{ Chinese } & \multicolumn{2}{|c|}{ White } \\
\hline & $\%$ & $95 \% \mathrm{Cl}$ & $\%$ & $95 \% \mathrm{Cl}$ & $\%$ & $95 \% \mathrm{Cl}$ & $\%$ & $95 \% \mathrm{Cl}$ & $\%$ & $95 \% \mathrm{Cl}$ \\
\hline \multicolumn{11}{|l|}{ Doctor } \\
\hline Consultant & 36.8 & 34.9 to 38.7 & 48.4 & 47.7 to 49.1 & 35.8 & 33.6 to 38.1 & 40.3 & 37.7 to 42.9 & 55.2 & 54.6 to 55.7 \\
\hline \multicolumn{11}{|c|}{ Nurses and health visitors } \\
\hline
\end{tabular}

Support to doctors, nurses and midwives

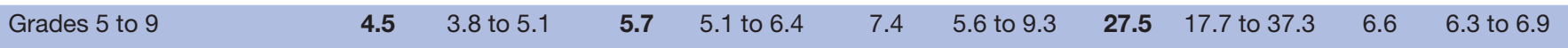

Table 3 displays the percentages and 95\% confidence intervals of higher job prestige by race/ethnicity for women. This information is displayed graphically in figure 2. Additionally, table 4 displays the percentages and $95 \%$ confidence intervals of higher job prestige by race/ ethnicity for men. This information is displayed graphically in figure 3 . The pattern of job prestige by race/ ethnicity for men and women is similar to the pattern found for the overall sample described above.

\section{Gender}

In general, within the NHS, men were nearly three and a half times more likely to be doctors than women: $22.4 \%$ (95\% CI $22.2 \%$ to $22.6 \%)$ of the men in the data were employed as doctors compared with only $5.4 \% \quad(95 \%$ CI $5.4,5.5$ ) of the women (calculations not shown). The greater likelihood for men to be doctors compared with women persisted throughout different race-ethnic groups. As shown in tables 3 and 4, gender differences were largest among white people for doctors. Within the NHS, white men were four times as likely to be employed as doctors compared with white women $(16.9 \% \quad(95 \%$ CI $16.7 \%$ to $17.0 \%$ ) vs $4.2 \%$ (95\% CI $4.1 \%$ to $4.2 \%)$ ). Gender differences were smallest among Chinese people where Chinese men were twice as likely to be doctors compared with Chinese women $(65.4 \%$ (95\% CI $63.3 \%$ to $67.4 \%$ ) vs $31.7 \%$ (95\% CI $30.5 \%$ to $32.8 \%))$. Men were also more likely to be consultants than women: $34.2 \%$ (95\% CI $33.8 \%$ to $34.6 \%$ ) of female doctors were consultants compared with $51.1 \%$ (95\% CI 50.7, 51.5) of male doctors (calculations not shown). Within each race-ethnic group we found a similar pattern, with male doctors more likely to be consultants than female doctors. We found a similar pattern also for nurses and health visitors and for support for doctors, nurses and midwives, with men in the higher paid bands than women. This gender disparity persisted across race-ethnic groups.

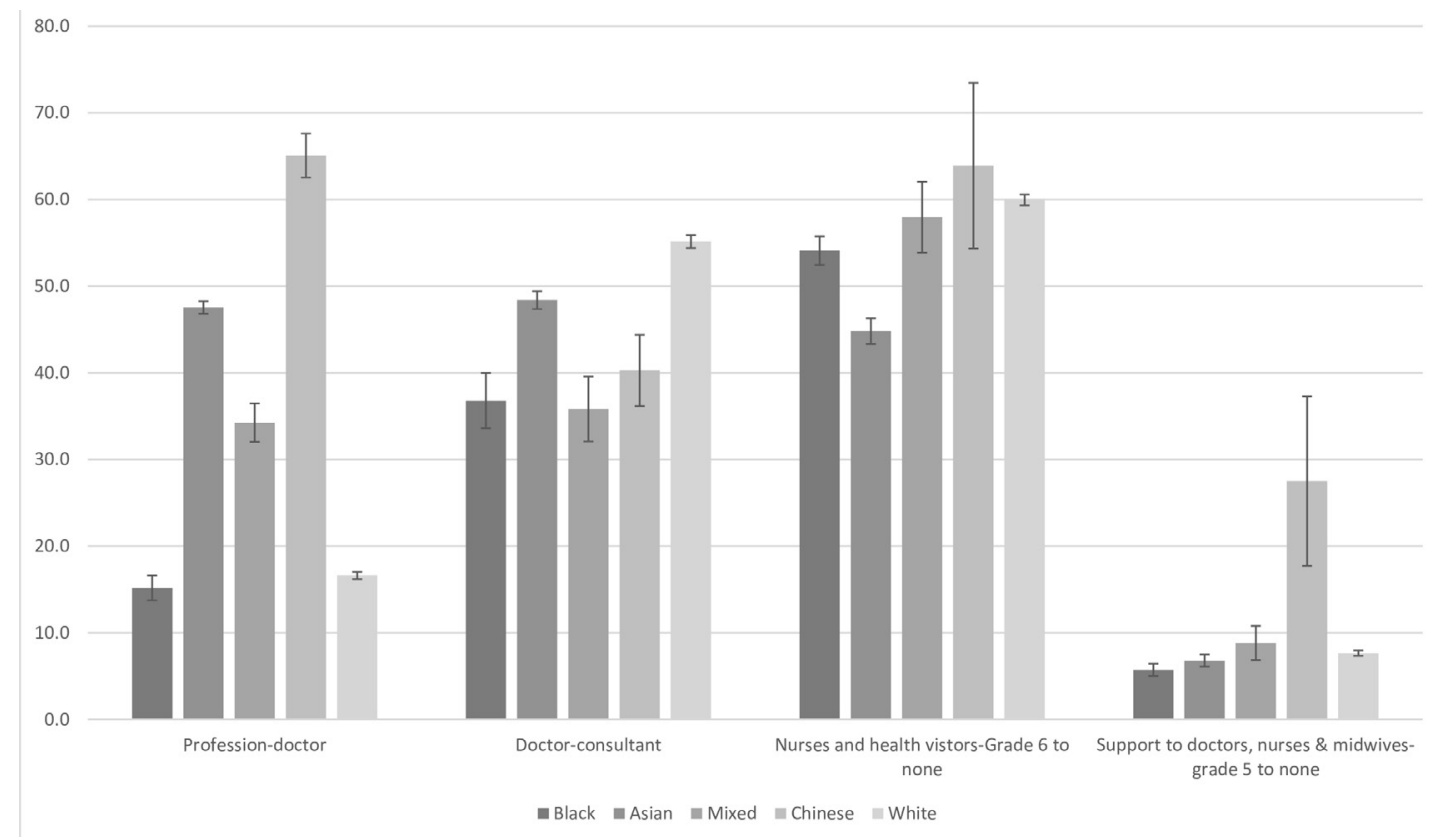

Figure 3 Percentage of those in the highest band in the medical profession by race/ethnicity: men. 


\section{DISCUSSION}

Our analyses found important differences in who becomes doctors compared with other professions, and which doctors have a more prestigious position and are on a higher pay band. We found that although Chinese people working in the NHS are more likely to be employed as doctors than other race-ethnic groups, they are less likely to be in the most prestigious group of doctors-consultants. In contrast, while only a small proportion of white people employed by the NHS are doctors, they were the most likely to be employed as consultants. Black people working in the NHS were doubly disadvantaged, having a low prevalence among doctors and, within the doctor groups as consultants. Examination of gender differences in the NHS showed that men were more likely than women to be employed as doctors, and within doctors, as consultants. This was true for all the race-ethnic groups examined here. We found a similar relationship between race/ethnicity, gender and prestige among nurses and health visitors. However, among support staff for doctors, nurses and midwives, we found that Chinese people are more likely to occupy the higher prestige jobs.

Other studies have examined race-ethnic pay disparities in the NHS, but most of this research has focused on differences between consultants and non-consultants among doctors and has failed to examine gender and race-ethnic disparities. ${ }^{1-3}$ We examine disparities in the prevalence of doctors by race/ethnicity, and by prestige within doctors (consultants compared with non-consultants), nurses and health visitors (grades 1 to 5 compared with 6 to 9) and support for doctors, nurses and midwives (grades 1 to 4 compared with grades 5 to 9 ). Additionally, we examine gender differences within and across race-ethnic groups.

The results of our study indicate that the NHS continues to favour white candidates ${ }^{8}$ and male candidates for the most prestigious and best compensated positions, even when they are statistically less likely to be represented in the applicant pool, such as in the case of white consultants. This has a negative effect on race-ethnic minorities and women working in the NHS, and the lack of diversity in prestigious and decision-making NHS positions is likely to have adverse public health consequences. Thus, the NHS should seek to reduce bias in hiring and promotions through other measures, such as requiring those involved in the decision-making process to undertake training, ensuring that committees are diverse and that applications are blinded.

One limitation of our study is that we excluded those from our analyses whose race/ethnicity was not stated, unknown or outside the categories used in our analyses (Black, Asian, Chinese, mixed race/ethnicity or White). We also excluded those in the nurses and health visitor and support to doctors, nurses and midwives categories whose pay grade was not listed in the current Agenda for Change system (Agenda for Change does not apply to doctors). An additional limitation is that we used cross-sectional data from one time point. Research using multiple time points is needed to examine how potential NHS initiatives ensure equality in hiring and promotion decisions over time. For this to be feasible, the NHS must also use consistent raceethnic categories to examine longitudinal differences. These longitudinal data may also provide insight into potential race/ethnic disparities and improvements over time in other areas of the NHS apart from prestige and pay, such as board membership, retention and pensions.

\section{Twitter Samir Jeraj @sajeraj}

Contributors AM, EB, SJ and JB were involved in the design of the study. AM and $E B$ carried out the statistical analysis and wrote the first draft of the manuscript with the support of SJ and JB. All authors participated in further drafts and approved the final manuscript. The corresponding author confirms that all listed authors meet authorship criteria and that no others meeting the criteria have been omitted. AM is the guarantor.

Funding SJ and JB are supported by the Health and Wellbeing Alliance grant, funded by the Department of Health and Social Care. JB was supported by a grant from NHS England during conduct of the study These funding sources had no role in the design or conduct of the study, the collection, management, analysis and interpretation of the data, or preparation, review or approval of the manuscript.

Competing interests $\mathrm{AM}, \mathrm{EB}$ and SJ have no other relationships or activities that could appear to have influenced the submitted work. JB sits on the Workforce Race Equality Standard strategic advisory group. They oversee the implementation of a work programme to deal with racial inequality in the employment of staff in the NHS.

Patient consent for publication Not required.

Provenance and peer review Not commissioned; externally peer reviewed.

Data availability statement Data are available in a public, open access repository. Data are available upon reasonable request.

Open access This is an open access article distributed in accordance with the Creative Commons Attribution Non Commercial (CC BY-NC 4.0) license, which permits others to distribute, remix, adapt, build upon this work non-commercially, and license their derivative works on different terms, provided the original work is properly cited, appropriate credit is given, any changes made indicated, and the use is non-commercial. See: http://creativecommons.org/licenses/by-nc/4.0/.

ORCID iD

Adrienne Milner http://orcid.org/0000-0003-3209-6185

\section{REFERENCES}

1 Moberly T. Doctors from ethnic minority backgrounds earn less than white colleagues. BMJ 2018;363.

2 Gov.uk. NHS workforce. Available: https://www.ethnicity-facts-figures. service.gov.uk/workforce-and-business/workforce-diversity/nhsworkforce/latest [Accessed 30 Nov 2018].

3 Appleby J. Ethnic pay gap among NHS doctors. BMJ 2018;362.

4 Anderson LM, Scrimshaw SC, Fullilove MT, et al. Culturally competent healthcare systems. A systematic review. Am J Prev Med 2003;24:68-79.

5 Kline R. The Snowy white peaks of the NHS: a survey of discrimination in governance and leadership and the potential impact on patient care in London and England, 2014. Available: https://www.mdx.ac.uk/ data/assets/pdf_file/0015/50190/The-snowy-white-peaks-of-the-NHS. pdf.pdf [Accessed 20 Dec 2019].

6 Salway S, Turner D, Mir G. High quality healthcare commissioning: why race equality must be at its heart. . Race Equality Foundation, 2013: 27. 1-6. http://raceequalityfoundation.org.uk/health-care/highquality-healthcare-commissioning-why-race-equality-must-be-at-itsheart/

7 NHS Digital. NHS workforce statistics, September 2017, provisional statistics. Available: https://digital.nhs.uk/data-and-information/ publications/statistical/nhs-workforce-statistics/nhs-workforcestatistics-september-2017-provisional-statistics\#key-facts [Accessed 21 Dec 2017].

8 Kline R. Discrimination by appointment: how black and minority ethnic applicants are disadvantaged in NHS staff recruitment, 2013. Available: http://www.publicworld.org/files/Discrimination_by_ appointment.pdf 